Disponível em:

http://editora.unoesc.edu.br/index.php/race

Race, Joaçaba, v. 15, n. 3, p. 1087-1116, set./dez. 2016

\title{
CARICATURAS E ESTEREÓTIPOS DO CONTADOR: COMO A IMAGEM DO PROFISSIONAL DE CONTABILIDADE VEM SENDO VEICULADA EM UM JORNAL DE GRANDE CIRCULAÇÃO NO BRASIL?
}

\begin{abstract}
Cartoons and acaccounter stereotypes: how accounting professional image comes in a newspaper being conveyed large circulation in Brazil?
\end{abstract}

Vinícius de Lacerda Miranda E-mail: vinicius-dlm@hotmail.com Graduando em Ciências Contábeis pela Universidade Estadual de Feira de Santana.

Juliano Almeida de Faria

E-mail: profjalmeida@gmail.com Mestre em Contabilidade pela Universidade Federal da Bahia; Doutorando em Engenharia Industrial com foco da pesquisa em Gestão Ambiental pela Universidade Federal da Bahia; Professor da Universidade Estadual de Feira de Santana. Endereço para contato: Av. Transnordestina, s/n, Novo Horizonte, 44036-900, Feira de Santana, Bahia, Brasil.

Artigo recebido em 19 de janeiro de 2016. Aceito em 21 de junho de 2016. 


\section{Resumo}

No contexto atual, o contador é peça fundamental no desenvolvimento das organizações e tem se destacado, sobretudo, na elaboração e controle das informações patrimoniais. No entanto, para o senso comum, essa categoria é percebida como um conjunto de profissionais limitados, sem criatividade e ligados a atividades rotineiras. Parte dessa percepção é influenciada diretamente pelos jornais de grande circulação, haja vista que, havendo notícias relacionadas à classe, estas serão publicadas pelos diversos meios de comunicação e de alguma maneira atingirão o público em geral. Porém, pouco foi discutido sobre como a imagem do profissional de contabilidade é tratada nos jornais de grande circulação no Brasil. Desse modo, este trabalho destina-se a preencher um pouco essa lacuna, trazendo uma luz sobre a disseminação da imagem do profissional de contabilidade em um jornal de grande mídia brasileira. Para tanto, foi feito um levantamento sobre os principais termos que envolvem a contabilidade, como contador, contábeis, contábil e contabilidade no banco de dados do Jornal Folha de São Paulo, durante um ano, de novembro de 2013 a novembro de 2014. A intenção foi perceber que tipo de imagem sobre o contador mais se perpetua, negativa ou positiva. Além disso, nesta pesquisa buscouse observar quais os termos mais associados à contabilidade e ao contador; as recorrências desses resultados podem estar contribuindo para que o senso comum mantenha uma imagem distorcida da realidade da categoria contábil.

Palavras-chave: Representação social. Imagem do contador. Contabilidade.

\section{Abstract}

In the current context, the accounter is a key part in the development of organizations and has been highlighted, particularly in the design and control of asset information. However, common sense, this category is perceived as a set of limited professional, uncreative and linked to routine activities. Part of this perception is influenced directly by major newspapers, given that, with news related to the class, they will be published by various media and somehow reach the general public. However, little has been discussed about the image of the accounting professional is treated in major newspapers in Brazil. Thus, this work aims to fill some of this gap, bringing a light on the spread of the accounting professional image in a large Brazilian media newspaper. Thus, a survey was done on the main terms involving accounting, as an accountant, accounting, accounting and bookkeeping in the database of the newspaper Folha de São Paulo, for a year, from November 2013 to November 2014. The intention it was to see what kind of image on the accounter longer perpetuates negative or positive. In addition, this study sought to observe that the most associated terms accounting and accounter; recurrences of these results may be contributing to the common sense keep a distorted picture of the accounting category reality.

Keywords: Social representation. Accounter image. Accounting. 


\section{INTRODUÇÃO}

Desde o advento da Revolução Industrial, ocorrida no século XVIII, o mundo assiste a uma escalada constante nos processos de produção. Pela primeira vez na história da humanidade experimentara-se um aumento na fabricação de mercadorias que, se comparado com poucos anos antes, seria considerado impossível. Hobsbawm (1981) afirma que a Revolução Industrial foi responsável por transformar completamente as formas de se produzirem produtos e riquezas, permitindo, assim, a multiplicação do patrimônio da burguesia.

A dinâmica econômica que se montou a partir disso, até a atualidade, demonstra grande competitividade entre as organizações empresariais. Estas têm se dedicado a aprimorar o processo produtivo, seja no modo de fazer seja na necessidade de controle, o que denota, por exemplo, o crescimento de áreas como análise de custos, contabilidade gerencial, entre outras (STARK, 2007).

Dentro do contexto atual, o profissional da área contábil tem se destacado como um elemento primordial, sobretudo na elaboração e controle das informações patrimoniais. Essas informações, extraídas dos demonstrativos contábeis e financeiros da empresa, devem evidenciar todos os fatos da gestão e são fundamentais no processo de tomada de decisões. Por sua vez, a tomada de decisões, observando dados passados, pode orientar-se para ações futuras, ou seja, planejamento. Boas decisões podem levar a empresa a ganhos de mercado, redução de custos, maior rentabilidade e condições de competitividade, enquanto ações equivocadas podem incorrer em endividamento e comprometer seriamente o patrimônio da empresa. Dessa forma, reitera-se o quão importante é a contabilidade, já que ela tem o poder de gerar essas informações, que precisam ser as mais confiáveis possíveis.

Porém, a classe profissional contábil vem percebendo uma desvalorização de seus serviços. Segundo Noronha, Santana e Nunes (2009), o desconhecimento da Ciência Contábil por parte de seus usuários conduz a uma compreensão equivocada da profissão, que passa a ser relacionada com situações corriqueiras, como declaração de impostos e necessidades imediatas, muito aquém das reais possibilidades do contador. Somados a isso, escândalos de ampla repercussão mundial, como os casos da Enron, Arthur Andersen e WorldCom, e processos de falência de grandes empresas também contribuem para o fortalecimento dessa imagem no inconsciente popular. Situações como essas têm exigido dos representantes (ordens da classe, estudantes, profissionais e outros) ações contínuas que visam, entre outros aspectos, combater os estereótipos formados em torno da classe contábil. 
Santana e Faria (2013) afirmam que a respeito da imagem concebida sobre a profissão contábil no Brasil formou-se uma série de estereótipos, dos quais se apresentam: A contabilidade é para os tímidos; não é um agente muito criativo, talvez um pouco tímido e que, em alguns casos, suspeita-se de sua idoneidade profissional; memorizador de regulamentos governamentais e dominador de técnicas contábeis; cumpridor de dispositivos legais sem capacidade criativa; funcionário indireto do fisco e do Governo para cálculo e preenchimento de guias, pouco flexível e com baixa capacidade de liderança.

De modo mais amplo, Baldvinsdottir et al. (2009) identificaram que nos anos 1970 e 1980 a imagem do contador foi construída como uma pessoa responsável e racional. Na década de 1990, o contador foi apresentado como um homem de ação instruído, e mais recentemente, tem aparecido como uma pessoa mais hedonista, sobretudo em propagandas. Já Miley e Read (2012) confirmam que ele tem sido caracterizado na cultura popular como maçante e chato, mesmo que o mercado da bolsa de valores descreva de forma consistente esse estereótipo como negativo para a profissão.

Pode-se observar que os estereótipos formulados, e que permeiam o senso comum, apresentam o contador como uma categoria vulnerável ou limitado em ação (quando chamado de tímido ou pouco criativo), ou até mesmo de uma idoneidade suspeita. Esse tipo de mentalidade popular, que segundo Chartier (1990), é justamente o que um indivíduo tem em comum com outros homens do seu tempo, atinge de forma negativa não apenas a contabilidade enquanto ciência, mas também o profissional da classe, na medida em que ambos têm sua credibilidade posta em dúvida.

É interessante observar que, ao contrário do que afirmam esses estereótipos, a ética profissional é defendida pelas Instituições de Ensino Superior (IESs), na figura dos profissionais que ensinam nessa área (MACÊDO et al., 2010), assim como pelos principais órgãos de representação, pelos movimentos estudantis e no papel do auditor, muito respeitado e admirado (KNECHEL et al., 2006; MACÊDO et al., 2010). Além disso, segundo Santana e Faria (2013), para um profissional atingir o nível exigido pelo mercado de trabalho é preciso que ele saiba pensar estrategicamente e criticamente, conhecer técnicas de gerenciamento de recursos, perceber implicações legais e fiscais nos negócios, ter conhecimento em marketing, entre outros. Pode-se notar que existe uma distinção entre a imagem que o profissional contábil projeta para si e a sua representação social no Brasil.

Não é possível definir com precisão o ponto inicial em que a figura do contador começa a ser distorcida e associada a fraudes e escândalos financeiros, porém, casos de grande repercussão na história recente, como o da Arthur Andersen, Enron, 
Worldcom, Parmalat, Bombril, Mensalão e Daslu, por exemplo, nos quais foram comprovadas a existência de fraudes fiscais, suscitam dúvidas quanto à confiabilidade e utilidade dos relatórios e informações contábeis (MURCIA; BORBA, 2005; SILVA; FLOR, 2013), uma vez que o produto do trabalho é posto em xeque; consequentemente, algumas suspeitas recaem sobre a responsabilidade do profissional de contabilidade.

Em vários casos percebe-se a manipulação dos relatórios contábeis, de forma intencional, para melhorar a imagem da empresa no mercado (MURCIA; BORBA, 2005). Em casos assim, o usuário externo é induzido ao erro. Morais (2007) conclui que há algum tempo a imagem e o marketing do contador vêm sendo influenciados por esse tipo de escândalos públicos, os quais têm contribuído para o surgimento de estereótipos e a formação de uma representação social em que pairam a a dúvida e desconfiança em relação à honestidade e à responsabilidade da categoria. Por outro lado, segundo Guerra et al. (2011), a representação que o contador possui de si demonstra um profissional que desenvolve atividades complexas e dinâmicas, com constantes mudanças e desafios. Além disso, é fundamental que seja levado à risca o cumprimento do código de ética, evitando, assim, posturas que depreciam a profissão como um todo.

Logo, pode-se observar que enquanto o contador, de forma geral, percebe a si mesmo e sua categoria como profissionais dinâmicos, com múltiplas competências, responsáveis, cheio de desafios e éticos (GUERRA et al., 2011), existem aqueles profissionais que não respeitam o código de ética da profissão (GRILO, 2011), assim como também existem aqueles que se envolvem em fraudes contábeis (MURCIA; BORBA, 2005; SILVA; FLOR, 2013), o que possibilita a existência de representações variadas sobre a figura do contador.

São os elementos oriundos da cultura comum que formam as representações, essas imagens mudam de acordo com vários elementos, como, por exemplo, instrução, grupo social ao qual o indivíduo pertence, entre outros (CARVALHO, 2005). A Teoria das Representações Sociais (TRS) prediz que o entendimento dessas imagens passa pelo entendimento dos mecanismos que constroem essa imagem para a população (MOSCOVICI, 1978; OLIVEIRA; SILVEIRA, 1998); entre eles incluem-se os jornais de grande circulação. Dessa forma, podem-se realizar diversos questionamentos acerca da continuidade da imagem negativa do profissional de contabilidade, bem como as características da autoimagem do profissional e de sua classe e, por fim, a respeito da valorização da classe no que se refere a um elemento promotor das diversas representações sociais possíveis. 
Porém, considerando-se a imagem (representação social) do profissional de contabilidade evidenciada em algumas pesquisas como pouco criativo, tímido e de idoneidade profissional suspeita, e considerando-se o importante papel dos meios de comunicação na formação dessa representação pública diante de toda a sociedade, pergunta-se: Como a imagem do profissional de contabilidade vem sendo veiculada nas notícias evidenciadas em jornais de grande circulação no Brasil?

Os jornais possuem grande influência na sociedade, inclusive na formação de opiniões. Silva e Flor (2013) mencionam que ainda hoje não é plenamente conhecida a forma como a mídia, em particular os jornais, trata o contador, e que sua opinião pode influenciar a imagem que o senso comum possui sobre a categoria. Partindo dessa premissa, o principal objetivo neste trabalho foi verificar como a imagem do profissional de contabilidade vem sendo veiculada nas notícias evidenciadas em um jornal de grande circulação no Brasil. Especificamente, foi feita uma análise de quais características estão associadas nas matérias do jornal à imagem do profissional contábil e da prevalência dessas imagens, sobretudo no que se refere a um profissional contábil associado a fraudes e ações antiéticas.

É importante analisar a perspectiva que os jornais apresentam sobre os contadores, isso porque se deve considerar a influência que os periódicos de grande circulação têm sobre a construção do imaginário coletivo, afinal, a imagem dos contadores tem implicações para o desenvolvimento da profissão contábil (BALDVINSDOTTIR et al., 2009). Atributos da imagem do profissional de contabilidade têm sido percebidos em estudos em várias partes do mundo, como visto nos trabalhos de Molinari e Riccio (2004), Knechel et al. (2006), Warren e Parker (2009), Evans e Fraser (2012), Miley e Read (2012) e Faragalla (2015). Todos esses trabalhos abordam aspectos ligados à construção/percepção da imagem do profissional de contabilidade perante a sociedade.

Nesse sentido, outras categorias profissionais também têm se preocupado com a forma que são representadas nos periódicos. O trabalho de Silva, Borges e Barbosa (2014) identifica como a imagem de profissionais da área do direito, especificamente advogados, é disseminada em jornais no Estado da Paraíba. A análise de 382 reportagens identifica aspectos centrais na construção da identidade profissional, como a influência do exercício profissional e do órgão de representação na sociedade, a atribuição de importância ao poder e a capacitação entre as preocupações dos profissionais. Os autores ainda concluem que essa identidade está relacionada às tradições históricas do País, ou seja, às ações político-associativas e às subcategorias referentes ao exercício profissional. 
Enquanto advogados possuem uma "boa imagem”, como citado anteriormente, Nauderer e Lima (2005) afirmam que a figura dos enfermeiros é identificada com distorções e, muitas vezes, com desvalorização social, por não serem devidamente reconhecidos pelo público. Além disso, o espaço ocupado pela enfermagem nos periódicos tem contribuído para reforçar os aspectos negativos. Assim como os enfermeiros, Ferreira (2012) afirma que, quando se trata dos professores, os jornais apresentam uma imagem pejorativa. A autora cita, ainda, que existe uma repetição no modo de construir o sentido sobre esse profissional e que este está excluído de se colocar como agente transformador.

A influência dos discursos emitidos pelos periódicos se deve especialmente à grande penetração social que estes possuem. Silva e Flor (2013) afirmam que a mídia possui grande influência sobre a sociedade e ressaltam que o que torna as informações jornalísticas valorizadas e aceitas pela sociedade é a credibilidade que a própria população atribui aos jornais.

Cruz (2012) afirma que os jornais consistem em um dos principais meios de mediação da sociedade e, dessa forma, a mídia tradicional “[...] constrói mitos e estereótipos, sugere regras, maneiras de pensar, modas e hábitos.” (CRUZ, 2012, p. 798). Pode-se observar, então, que a mídia de massa possui um poder discursivo significativo, e esse poder, por ser oculto, tem grande eficácia, muitas vezes, levando o leitor a tomar como verdadeiras as informações fornecidas nos jornais, diante da verificação dos fatos.

Outra importância atribuída ao presente estudo é dar continuidade e aprofundamento à pesquisa de Silva e Flor (2013), que partem de uma temática semelhante: analisar como o contador é tratado pela imprensa jornalística brasileira. Porém, a atual análise diferencia-se e se justifica por focar no ano 2014, adotando um recorte temporal mais recente e, por isso, mais atual sobre a imagem do profissional.

Além disso, nesta pesquisa há uma ampliação na quantidade de termos pesquisados em comparação à pesquisa de Silva e Flor (2013), objetivando uma imagem mais completa sobre a visão que o periódico possui sobre a contabilidade em geral. Por fim, amplia-se a discussão ao inserir a análise à luz da TRS já discutida como teoria útil na identificação da representação social do profissional de contabilidade por Santana e Faria (2013).

Considerando-se a representação social apontada em outras pesquisas sobre a categoria contábil (SANTANA; FARIA, 2013), é interessante observar quais dessas características são veiculadas pelos jornais, o que pode indicar a influência desse tipo de mídia na construção de estereótipos da imagem do profissional. Isso é relevante 
para a classe, pois permite conhecer, por meio de uma pesquisa científica em um conglomerado de informações disseminadas em um periódico de grande circulação, dos últimos 12 meses, quais características estão associadas à sua imagem, de modo a possibilitar traçar ações de veiculação de imagem mais adequada do profissional contábil, segundo a profissão prediz.

Por fim e não menos importante, esta pesquisa pode auxiliar os estudantes da área, ao longo do seu processo de conhecimento da profissão, a estarem mais conscientes das características mais noticiadas na mídia por meio do jornal em nível nacional, além de contribuir para o enriquecimento das discussões em sala motivadas pelos profissionais de ensino.

\section{REFERENCIAL TEÓRICO}

\subsection{A IMAGEM DO PROFISSIONAL CONTÁBIL}

Para melhor compreender a discussão aqui apresentada, foram elencados alguns dos conceitos norteadores do desenvolvimento desse processo de pesquisa. Inicialmente, o artigo de Guerra et al., (2011) introduz as primeiras noções sobre o conceito de representação social. Por meio da utilização da psicologia social, eles definem que representação social seria uma forma de conhecimento socialmente elaborada e compartilhada, que tem um objetivo prático e concorre para a construção de uma realidade comum a um conjunto social.

É uma contribuição importante à medida que a discussão apresenta uma perspectiva de análise de um objeto a partir de uma representação coletiva (senso comum). Essas representações não são um agregado de pensamentos individuais, são, porém, reflexo de processos construídos dentro da sociedade, construídos por grupos diferenciados por suas posições e ações sobre os objetos, podendo assumir uma simbolização e novas interpretações sobre ele (MOSCOVICI, 2003; GUERRA et al., 2011).

O profissional contábil entende-se como ético, responsável, amigo e em constante evolução (GUERRA et al., 2011). Essa imagem a qual ele tem de si serve de parâmetro e de ponto de partida para procurar entender em que momento o coletivo passou a construir uma representação contrária, ou dissociada desta.

Silva e Flor (2013) apresentam uma perspectiva diferente; segundo eles, a sociedade percebe o profissional contábil como limitado, pouco qualificado e sem entusiasmo pela profissão, sendo normalmente associado com apuração de impostos, escrituração de serviços de cartórios e segundas vias de documentos, o que notada- 
mente é uma visão simplista da função. Os autores afirmam, também, que além dos escândalos noticiados na mídia envolvendo contadores, outro motivo que contribuiu para essa desconfiança sobre a categoria se deve à relação de subordinação perante o empregador, já que os profissionais, sob a ameaça de perderem o emprego, “[...] são impelidos a realizar 'maquiagens’ na contabilidade para camuflar possíveis fraudes da companhia.” (SILVA; FLOR, 2013, p. 64).

Morais (2007) corrobora Guerra et al. (2011), principalmente quando afirma que muitas atitudes tomadas no dia a dia, como comprar, votar, escolher serviços, entre outros, muitas vezes não se baseiam em atitudes lógicas ou racionais, mas por razões baseadas nos campos simbólico, mítico, religioso ou afetivo. Morais (2007, p. 38) afirma, ainda, que o estudo das representações sociais é importante por “[...] chamar a atenção a essa realidade e tenta mostrar a importância de se conhecer essas representações para se compreender o comportamento das pessoas, no tocante a criação de uma imagem.”

O autor, ao enfatizar o fato de que muito das opiniões que circulam, principalmente no senso comum, são mais emotivas do que racionais, demonstra que não se sabe ao certo a origem desse juízo de valor, mas à medida que se ganha popularidade, as pessoas se inclinam a aceitá-lo como verdadeiro. Essas representações são originárias nas comunicações interpessoais, que ocorrem principalmente na vida cotidiana, e estudá-las é tentar perceber de que forma um grupo social constrói um conjunto de saberes o qual expressará sua identidade (MORAIS, 2007).

Sobre essa ótica, Morais (2007) tenta definir qual deveria ser o comportamento e a postura que o profissional de contabilidade deve assumir perante a sociedade e qual a imagem que deve representar. Para isso, o contador devia lançar mão do marketing pessoal, que seria uma das principais funções do profissional para agregar valor à sua função, além de solidificar a representação social. Contudo, deveriam ser repensados os cursos de formação nas Instituições de Ensino Superior (IESs), para que estes fornecessem o arcabouço necessário para esse profissional saber como construir sua imagem perante a comunidade.

\subsection{GENEALOGIA E REPRESENTAÇÃO SOCIAL}

Para se entender como foi construído esse estereótipo sobre a figura do contador ao longo do tempo, este estudo apoia-se na noção de genealogia foucaultiana, que se refere à formação efetiva dos discursos, analisando tanto o esgotamento das ideias quanto o agrupamento e unificação desses discursos (FAÉ, 2004). Pois se compreende 
que a construção das representações caricatas sobre o profissional não foi estabelecida de forma contínua e linear, mas, sim, ao longo de sucessivos eventos aparentemente aleatórios que se interligam e acrescentam novas referências sobre o objeto analisado. Por isso, o uso da genealogia, ou, como define Williams (2012), intricadas descrições da emergência, ao longo da história, de formas de poder que operam no presente.

Além do mais, dentro da visão foucaultiana, teses sobre longos períodos históricos inevitavelmente se chocam com rupturas (FOUCAULT, 1979), ou seja, por mais que determinada classe tenha se construído ou tente se construir como totalmente ética e responsável, em algum momento ao longo de sua história determinados eventos aconteceram de forma repercussiva, para que fosse montada no imaginário coletivo uma imagem contrária. E, por mais que esses eventos tenham sido um ou mais casos isolados, a busca sobre essa construção se justifica no ponto em que se deseja uma melhoria na representação e, quiçá, nos próprios serviços prestados pelo contador.

Ainda segundo Foucault (1979, p. 19):

Fazer genealogia dos valores, da moral, do ascetismo, do conhecimento não será, portanto, partir em busca de sua “origem”, negligenciando como inacessíveis todos os episódios da história; será, ao contrário, se demorar nas meticulosidades e nos acasos dos começos; prestar uma atenção escrupulosa à sua derrisória maldade; esperar vê-los surgir, máscaras enfim retiradas, com o rosto do outro; não ter pudor de ir procurá-las lá onde estão, escavando os bas-fond.

Logo, fazer uma análise genealógica não é partir em busca de uma semente original, um começo, mas procurar todos (enquanto possível) os eventos históricos que construíram no presente as circunstâncias atuais. Por meio da genealogia percebe-se que as práticas discursivas atravessam e são atravessadas pelo saber do senso comum e também quais as condições que possibilitaram o surgimento e a permanência dessas práticas. Essa perspectiva fornece o cabedal teórico para compreender a construção histórica que permitiu a emergência desses discursos (FAÉ, 2004).

Apesar de os estudos supracitados tratarem de representação social, partem de uma linha de análise da Psicologia, por isso, outro pensador importante utilizado para o desenvolvimento dessa pesquisa, que irá agregar na construção desse conceito, será Roger Chartier, considerando-se que uma de suas grandes contribuições para a história cultural é justamente a elaboração de noções sobre práticas e representações (CARVALHO, 2005). 
Segundo Carvalho (2005, p. 149), pode-se entender o conceito de representações, à luz da obra de Chartier (1990), como:

As representações são entendidas como classificações e divisões que organizam a apreensão do mundo social como categorias de percepção do real. As representações são variáveis segundo as disposições dos grupos ou classes sociais; aspiram à universalidade, mas são sempre determinadas pelos interesses dos grupos que as forjam. O poder e a dominação estão sempre presentes. As representações não são discursos neutros: produzem estratégias e práticas tendentes a impor uma autoridade, uma deferência e mesmo a legitimar escolhas.

Ou seja, segundo Carvalho (2005), à luz de Chartier (1990), as representações (por mais que se construam no campo do senso comum, como a Psicologia afirma) são imbuídas de uma opinião do grupo que formou ou legitimou essa opinião. Considerando esse conceito, pode-se dizer, então, que as suspeitas levantadas sobre a idoneidade moral do profissional, citadas por Santana e Faria (2013), não foi algo totalmente espontâneo, mas, em algum momento, algum grupo manifestou e veiculou essa ideia por qualquer interesse particular, e posteriormente isso acabou se reproduzindo nos diversos círculos sociais, visto que os jornais são importantes meios de comunicação dentro do contexto.

No entanto, as representações sociais não são apenas opiniões de um grupo impostas ao público comum, elas se relacionam com o cotidiano, “[...] elas se constituem através de várias determinações sociais para, em seguida, tornarem-se matrizes de classificação e ordenação do próprio mundo social.” (CARVALHO, 2005, p. 151). Dessa forma, a representação sobre os contadores seria formada em dois momentos, dentro da relação destes com os seus usuários e no contato do público com as notícias emitidas pela mídia em geral (e reapropriação de seus significados). Assim, essa perspectiva se encaixa com a noção de genealogia quando afirma que as práticas discursivas atravessam e são atravessadas pelo saber comum.

\subsection{O CONTADOR E A ÉTICA PROFISSIONAL}

Para definir a representação social do contador na perspectiva dos próprios profissionais em atuação na área, Guerra et al. (2011) realizaram entrevista com profissionais que atuaram na Cidade de Ribeirão Preto, São Paulo, no ano 2011. Os resultados indicaram que, para os contadores, eles possuem diversas áreas de atuação, 
o que exige permanente atualização de conhecimentos, sendo, portanto, um ofício em constante evolução e cheio de desafios. Assim, a profissão é tida como de muita responsabilidade. Além disso, os entrevistados destacam que a profissão é adorada por quem a pratica.

Portanto, a representação que o contador possui de si demonstra uma atividade complexa e dinâmica, com constantes mudanças e desafios, o que requer dele uma capacitação em várias áreas e de forma contínua. Segundo Grilo (2011), para o profissional manter o comportamento social esperado, ele necessita, além de qualificação técnica, de uma postura calcada nos princípios éticos, os quais estão claramente dispostos no código de ética, que regulamenta e norteia as atividades do serviço contábil.

É fundamental que seja levado à risca o cumprimento do código de ética, evitando-se, assim, posturas que depreciam a profissão como um todo. Ainda nesse sentido, o código afirma, também, que é desonroso compactuar com práticas desabonadoras e que são agravadas quando se constata o incentivo destas por parte do contador, sob o pretexto de ser diligente e objetivando a simpatia do cliente (GRILO, 2011). Esse autor afirma, ainda, que o contador enfrenta muitos dilemas éticos no exercício de sua função, e mais, a não observância do Código de Ética tem sido constantemente praticada por parte de alguns profissionais, mesmo que reconhecida a sua existência e importância. Essa afirmação de Grilo (2011, p. 20-21) é corroborada pelos dados publicados pelo CRC/BA no que se refere às infrações éticas/disciplinares abordadas pela sua fiscalização no primeiro semestre de 2014, que totalizaram 179 ocorrências.

Qualquer atividade ilícita praticada fere o código de ética, entretanto, de forma mais específica, Murcia e Borba (2005) afirmam que as fraudes contábeis são aquelas cometidas em prol da organização. Em vários casos manipulam-se os relatórios contábeis, de forma intencional, para melhorar a imagem da empresa no mercado, seja inflando lucros seja omitindo dados (MURCIA; BORBA, 2005). Em casos assim, o usuário externo é induzido ao erro, haja vista que as informações oferecidas não condizem com a real situação patrimonial da instituição.

Morais (2007) conclui que há algum tempo a imagem e o marketing do contador vêm sendo pressionados por esse tipo de escândalos públicos que envolvem fraudes contábeis e que têm contribuído para o surgimento de estereótipos e a formação de uma representação social em que pairam a dúvida e a desconfiança em relação à honestidade e à responsabilidade da categoria.

Nesse sentido, Grilo (2011), em sua pesquisa, constatou que 46,43\% dos profissionais analisados na amostra acreditam que os contadores da Cidade de Feira de Santana, para atenderem às vontades dos clientes e até mesmo para conseguirem 
novos, deixam de observar o zelo, a diligência e a honestidade. Um dos motivos para tal comportamento seria o número elevado de profissionais na Cidade e o fato de que essa concorrência influenciaria diretamente no comportamento e na conduta ética dos profissionais.

Independente dos motivos, a não observância do código de ética por parte dos profissionais incorre em um desgaste da categoria com a opinião pública, no caso dos contadores, e por mais que o CRC mantenha uma fiscalização, esse tipo de ação por parte dos profissionais autuados pode influenciar o imaginário popular a manter uma imagem negativa da categoria.

\subsection{A INFLUÊNCIA DA MÍDIA}

A comunicação humana acontece inevitavelmente por meio da mediação da linguagem. Seguindo essa noção, percebe-se que a mídia de massa atua como mediadora entre os fatos e o leitor (YARED, 2011). Além disso, as empresas de comunicação são fundamentais na formação do intelecto e da personalidade do indivíduo, de forma que, durante o processo de comunicação, as partes envolvidas, mídia e leitores, são influenciadas umas pelas outras (SILVA; FLOR, 2013).

Fischberg (2011) diz que estamos sendo educados a todo o momento por imagens e sons e muitos outros meios oriundos das mídias; isso também atribui aos meios de comunicação uma responsabilidade nos processos culturais e educativos. "Afinal, as mídias não só asseguram formas de socialização e transmissão simbólica, mas também participam como elementos importantes da nossa prática sociocultural na construção de significados da nossa inteligibilidade do mundo.” (FISCHBERG, 2011, p. 14).

Durante a rotina de um jornal, para se escolher uma notícia, o fator econômico é o primeiro a ser considerado, observando-se que a venda dos exemplares é o principal motivo que mantém vivo um jornal. Yared (2011) menciona que a mídia se autointitula portadora de um discurso da verdade dos fatos, e o leitor, por sua vez, pressupõe que aquilo que lê é uma representação fiel do ocorrido. Isso acontece porque o senso comum acredita que o que a mídia escreve não possui nenhum caráter fictício ou parcial. Assim, o público comum pode não questionar as notícias apresentadas, no caso de acreditar que o que consta no jornal é o conteúdo que realmente deveria ter, sem perceber que foi um conteúdo selecionado, em detrimento de outros, pelo editorial daquele meio de comunicação (YARED, 2011).

Silva e Flor (2013) confirmam o argumento de que a mídia possui grande influência na sociedade, principalmente quando afirmam que o principal motivo que 
torna as informações jornalísticas valorizadas e aceitas pela sociedade é a credibilidade que a própria população atribui aos jornais, mesmo hoje com outros meios de informação, como internet e televisão.

É importante observar, porém, que a mídia consiste em um espaço no qual as mais diversas forças da sociedade se confrontam, os veículos de comunicação reproduzem o conflito entre classes hegemônicas e de resistência. Entretanto, esses veículos de comunicação normalmente atuam alinhados com as forças hegemônicas, transmitindo, assim, suas opiniões e seus valores como certos e entendendo os demais como inferiores; cumplicidade essa que é reforçada por um discurso que omite e/ou manipula informações (CRUZ, 2012).

O autor afirma que os jornais consistem em um dos principais meios de mediação da sociedade, ao mesmo tempo que seus textos e imagens corroboram para o fortalecimento dos laços sociais e da homogeneização de discursos e identidades. Dessa forma, a mídia tradicional "[...] constrói mitos e estereótipos, sugere regras, maneiras de pensar, modas e hábitos.” (CRUZ, 2012, p. 798).

Pode-se observar, então, que a mídia de massa é detentora de uma força significativa, o poder discursivo, pois é ela que tem acesso à produção, reprodução e disseminação de discursos por meio da posse desses recursos (YARED, 2011). Esse poder discursivo está associado à representação social que a mídia jornalística dispõe na sociedade, e tem grande eficácia, o que pode conduzir o leitor a tomar como próprias as informações fornecidas nos jornais, diante da verificação dos fatos.

Nesse contexto, a TRS contribui para o entendimento do papel da mídia no processo de construção da imagem do profissional de contabilidade na atualidade, pois afirma que as representações sociais devem ser percebidas como uma atmosfera em relação ao sujeito e ao grupo, sendo, sob certos aspectos, específicas de nossa realidade (MOSCOVICI, 1978, 2003) na qual se inclui a mídia como fator intenso e influenciador da representação social.

\section{METODOLOGIA}

\subsection{CARACTERIZAÇÃO DA PESQUISA}

O presente estudo caracteriza-se como descritivo, pois compreende a observação de características, registra os dados selecionados, analisa os itens delimitados na pesquisa e os interpreta sem interferi-los (ANDRADE, 2002). Conforme Gil (2008), “A pesquisa descritiva tem como objetivo principal a descrição das características de 
determinada população ou fenômeno ou estabelecimento de relações entre variáveis”. Na coleta de dados para a pesquisa descritiva foram utilizados dois delineamentos de pesquisa: bibliográfica e documental. A primeira tem a vantagem de permitir ao pesquisador uma cobertura ampla de fenômenos, com materiais já elaborados constituídos principalmente de livros e artigos científicos. E a segunda diferencia-se da primeira apenas quanto à natureza das fontes (GIL, 2008).

Para a pesquisa documental foi escolhido o periódico de grande respaldo nacional, Folha de São Paulo, que disponibilizou todo o seu acervo em um banco de dados e acesso virtual. Por objetivar uma interpretação e expressão dos sentidos dos fenômenos existentes nos materiais analisados, este trabalho possui abordagem qualitativa. Segundo Neves (1996, p. 1), “[...] os estudos qualitativos compreendem um conjunto de diferentes técnicas interpretativas que visam descrever e decodificar os componentes de um sistema complexo de significados”. O desenvolvimento de um estudo de pesquisa qualitativa supõe um corte temporal-espacial de determinado fenômeno por parte do pesquisador (NEVES, 1996). No caso desta pesquisa, definiu-se o intervalo de tempo entre 11 de novembro de 2013 e 10 de novembro de 2014, sendo, assim, um ano por disponibilidade digital dos dados pelo Jornal.

O mecanismo utilizado para realizar o levantamento de dados para a pesquisa foi a análise de conteúdo. Conforme Bardin (1979, p. 42),

Análise de conteúdo é um conjunto de técnicas de análise de comunicação visando obter, por procedimentos sistemáticos e objetivos de descrição do conteúdo das mensagens, indicadores (quantitativos ou não) que permitam a inferência de conhecimentos relativos às condições de produção/recepção destas mensagens.

Para que o processo de explicação e explicitação do conteúdo da mensagem possa ocorrer de forma coordenada Bardin (1979) demonstra três etapas a serem cumpridas:

a) a pré-análise: fase de organização e sistematização das ideias, em que ocorre a escolha dos documentos a serem analisados;

b) a exploração do material: trata-se da fase em que os dados brutos do material são codificados para se alcançar o núcleo de compreensão do texto;

c) tratamento dos resultados obtidos e interpretação: nessa fase, os dados brutos são submetidos à interpretação. 
Na exploração do material foi realizada uma contagem direta dos termos; os termos encontrados com maior frequência foram categorizados conforme estratificação proposta por Silva e Flor (2013).

\subsection{LEVANTAMENTO DOS DADOS}

Ao longo do tempo o homem deixa marcas de sua passagem que, quando examinadas coerentemente, fornecem informações sobre aquele contexto social. Além disso, diversas fontes podem fornecer informações sobre grupos sociais específicos em um período determinado. No caso deste estudo, as fontes podem ajudar a compreender como o imaginário coletivo vê a classe contábil, e mais, permitem auxiliar na compreensão de como se reproduz a representação caricata desta. Nesta pesquisa documental foram utilizadas fontes primárias, também conhecidas pela historiografia como fontes originais, que são documentos da época. Destes, cita-se que esta pesquisa se concentrará na análise do Jornal, buscando principalmente o que se refere à classe contábil.

O foco da investigação foi o periódico de grande respaldo nacional, Folha de São Paulo, que disponibilizou todo o seu acervo em um banco de dados e acesso virtual. Por se tratar de um estudo histórico, definiu-se o intervalo de tempo entre 11 de novembro de 2013 e 10 de novembro de 2014, sendo, assim, um ano. Esse período foi escolhido por considerar a disponibilidade do acervo digital e para garantir que existam os dados para todo o espaço de tempo da pesquisa. Além disso, por ser um recorte atual, permite a esta pesquisa analisar qual o discurso do Jornal, também atual, sobre a categoria contábil.

A base de dados do Folha de São Paulo permitiu uma busca com fundamento em termos. Digitando dentro do buscador determinada palavra, foram apresentadas todas as ocorrências daquela expressão no Jornal nas últimas décadas. Assim, foi feito um levantamento na base sobre os termos contador, contábil, contábeis e contabilidade, os quais se acredita serem os mais utilizados para se referir à categoria. Não foram utilizados termos compostos, como, por exemplo, profissional contábil, pois ao se pesquisar a terminologia contábil, obrigatoriamente o primeiro termo integra os resultados da busca, da mesma forma que Ciências Contábeis e contábeis, sucessivamente. Em seguida, foram classificadas quais reportagens tratavam do contador e categoria, diretamente, e quais apenas mencionavam os referidos termos, sem uma relação direta com o ofício. Assim, as reportagens foram classificadas da seguinte forma: 
Quadro 1 - Classificação do tipo de reportagens

\begin{tabular}{|c|c|}
\hline A & $\begin{array}{l}\text { Relação direta com o contador e/ou sobre a utilização de demonstrativos contábeis. } \\
\text { Ex: "O contador moderno, cobiçado no mercado internacional, é comunicativo e tem amplo campo } \\
\text { de atuação." (BOMFIM, 2014). }\end{array}$ \\
\hline B & $\begin{array}{l}\text { Refere-se a um contador ou seus demonstrativos, mas sem relação com o ofício. } \\
\text { EX: “[...] sua profissão de contador autorizando-o, de todo modo, a desempenhar o papel sempre } \\
\text { bem-vindo de listar e contar os carapaus, merluzas, solhas, rodovalhos e outros linguados na volta } \\
\text { ao cais.” (ECHENOZ, 2014). }\end{array}$ \\
\hline $\mathrm{C}$ & $\begin{array}{l}\text { Classificados. } \\
\text { Ex: “M/F Supermercados admite c/ curso superior em ciências contábeis.” (FOLHA DE SÃO } \\
\text { PAULO, 2014a). }\end{array}$ \\
\hline $\mathrm{D}$ & Publicação de Atas e Demonstrativos Contábeis. \\
\hline $\mathrm{E}$ & $\begin{array}{l}\text { Outras definições. } \\
\text { Ex: "Tancredo era um bom contador de casos e, à noite gostava de nos contar histórias de assom- } \\
\text { bração." (NEVES, 2014). }\end{array}$ \\
\hline
\end{tabular}

Fonte: os autores.

Após a contagem de todos os dados e a classificação destes segundo o Quadro 1, para efeito de análise e atendimento do objetivo deste trabalho, são consideradas especificamente as informações do indicador “A”, que são aquelas que se relacionam diretamente com o ofício do contador ou que comentam sobre a utilização dos demonstrativos e relatórios contábeis, segundo classificação no Quadro 2:

Quadro 2 - Classificação de ocorrências diretas

\begin{tabular}{|c|l|}
\hline I & Relação direta com o ofício do contador, utilização de demonstrativos contábeis. \\
\hline II & Notas policiais vinculadas às fraudes contábeis. \\
\hline III & Escândalos políticos associados à profissão do contador. \\
\hline IV & Críticas ao modelo de gestão governamental com base em demonstrativos e resultados contábeis. \\
\hline
\end{tabular}

Fonte: os autores.

Após essa primeira classificação, as notícias foram dispostas de acordo com a imagem transmitida sobre o contador, ou seja, foram contadas como positivas, negativas e neutras.

Positiva sendo a notícia que destaca a importância da contabilidade ou como ela pode/deve ser utilizada em uma organização; neutra, a redação que não associa a profissão nem a boas e nem a más impressões; e negativas, as ocorrências que associam a contabilidade com casos polêmicos ou antiéticos.

Apesar de a investigação inicialmente proceder sobre um levantamento de dados, os quais demonstrarão a periodicidade com a qual esse canal de comunicação se refere à contabilidade, esses mesmos dados não são analisados apenas de forma 
qualitativa. A pesquisa qualitativa é crucial para o desenvolvimento das atividades porque permite entender os fenômenos in loco, ou seja, a partir do ponto de vista das pessoas que constroem a relação. Dessa forma, o trabalho de análise dos dados organiza-se conforme o Quadro 3.

Quadro 3 - Etapas de pesquisa qualitativa

\begin{tabular}{|l|l|l|l|}
\hline Etapas (Bardin, 1979) & \multicolumn{1}{|c|}{$\begin{array}{c}\text { Documentos } \\
\text { analisados }\end{array}$} & Dados brutos & Dados interpretados \\
\hline Pré-análise & $\begin{array}{l}\text { Edições do Jornal Folha } \\
\text { de São Paulo }\end{array}$ & Não se aplica & Não se aplica \\
\hline Exploração & Não se aplica & $\begin{array}{c}\text { Contador, Con- } \\
\text { tábeis, Contábil } \\
\text { e Contabilidade }\end{array}$ & Não se aplica \\
\hline Tratamentos & Não se aplica & Não se aplica & $\begin{array}{l}\text { Classificação das ocorrên- } \\
\text { cias diretas conforme o } \\
\text { Quadro 2. }\end{array}$ \\
\hline
\end{tabular}

Fonte: adaptador de Badin (1979).

Em se tratando de jornais, a historiografia já destaca e discute, desde a década de 1980, que por mais que as reportagens objetivem ter um caráter de neutralidade, podem estar carregadas de ideologias e doutrinas dos grupos que veiculam essa notícia (LUCA, 2005). Então, deve-se observar minimamente o discurso e o conteúdo, tarefas essenciais em uma pesquisa com fontes históricas.

Ainda sobre essa questão, Luca (2005) afirma que os periódicos selecionam, ordenam, estruturam e narram de determinada forma aquilo que eles próprios elegeram como digno de chegar até o público. Aquele que analisa os jornais deve dispor de ferramentas de análise de discurso, as quais o permitirão problematizar a narração do evento e o próprio acontecimento em si.

Estruturar o processo de análise dessa forma torna possível um caminho teórico-metodológico de como estudar a construção das identidades sociais partindo da comparação entre as representações impostas por aquele que possui o poder de veiculação dessas ideais e as representações construídas pela própria comunidade, seja de forma passiva seja pela resistência às imposições (MOSCOVICI, 2003).

Entende-se que para estudar a contabilidade em determinado período, deve-se fazer o papel de um historiador e criticar a forma como as informações foram transmitidas, somente a partir disso será possível perceber as características associadas à figura do profissional contábil. 


\section{RESULTADOS E DISCUSSÃO}

A pesquisa inicial da base de dados do Jornal Folha de São Paulo resultou em um total de 1.593 ocorrências para os termos contador, contábeis, contábil e contabilidade. Desse total, 93\% (1.483 ocorrências) possuem algum tipo de relação com o contador (categoria ou contexto de trabalho). Convém destacar que destes, 155 eventos falam sobre o profissional ou a contabilidade, mas apenas como citação, ou melhor, sem se relacionar propriamente com o ofício. Constatou-se que apenas 15\% (243) apresentam relação direta com o contexto, seja sobre decisões gerenciais calcadas em informações contábeis seja sobre os demonstrativos e relatórios contábeis.

É interessante destacar que 32\% das notícias (503) são sobre oferta e procura de empregos, portanto classificados, e 36\% dos casos, cerca de 582 eventos, estão relacionados ao Art. 289 da Lei n. 6.404/76, que determina que as sociedades anônimas de grande porte devem publicar seus relatórios contábeis em jornais de grande circulação, fato que reforça a importância do jornal escolhido, como de grande propagação e influência nacional.

Os outros 7\% (110 ocorrências) não se referem ao termo contador enquanto profissional contábil, nem relacionado à área contábil, mas tratam-se apenas de vocábulos homônimos, como, por exemplo, contador (de histórias, de casos, de poemas), assim como as expressões contabilidade e/ou contábil, que, nesses casos, estão ligadas à contagem numérica.

Tabela 1 - Total de ocorrências por mês - Folha de São Paulo

\begin{tabular}{|c|c|c|c|c|c|c|c|c|c|c|c|c|c|c|}
\hline $\begin{array}{l}\text { Ocor- } \\
\text { rências }\end{array}$ & $\begin{array}{c}\text { Nov. } \\
13\end{array}$ & $\begin{array}{c}\text { Dez. } \\
13\end{array}$ & $\begin{array}{c}\text { Jan. } \\
14\end{array}$ & $\begin{array}{c}\text { Fev. } \\
14\end{array}$ & $\begin{array}{c}\text { Mar. } \\
14\end{array}$ & $\begin{array}{c}\text { Abr. } \\
14\end{array}$ & $\begin{array}{c}\text { Mai. } \\
14\end{array}$ & $\begin{array}{c}\text { Jun. } \\
14\end{array}$ & $\begin{array}{c}\text { Jul. } \\
14\end{array}$ & $\begin{array}{c}\text { Ago. } \\
14\end{array}$ & $\begin{array}{c}\text { Set. } \\
14\end{array}$ & $\begin{array}{c}\text { Out. } \\
14\end{array}$ & $\begin{array}{c}\text { Nov. } \\
14\end{array}$ & Total \\
\hline $\begin{array}{l}\text { Relação } \\
\text { direta } \\
\text { Sem }\end{array}$ & 17 & 21 & 32 & 2 & 26 & 24 & 17 & 10 & 16 & 24 & 20 & 25 & 9 & 243 \\
\hline relação & 11 & 15 & 16 & 5 & 11 & 13 & 11 & 14 & 13 & 6 & 15 & 17 & 8 & 155 \\
\hline $\begin{array}{l}\text { direta } \\
\text { Classifi- } \\
\text { cados } \\
\text { Assina- }\end{array}$ & 20 & 47 & 53 & 14 & 54 & 32 & 52 & 53 & 44 & 63 & 33 & 23 & 15 & 503 \\
\hline $\begin{array}{l}\text { turas em } \\
\text { atas ou } \\
\text { balanços } \\
\text { Outras }\end{array}$ & 3 & 3 & 8 & 115 & 179 & 121 & 34 & 10 & 17 & 67 & 20 & 3 & 2 & 582 \\
\hline $\begin{array}{l}\text { defini- } \\
\text { ções }\end{array}$ & 1 & 8 & 9 & 3 & 8 & 14 & 6 & 9 & 34 & 6 & 4 & 7 & 1 & 110 \\
\hline $\begin{array}{l}\text { Total } \\
\text { por mês }\end{array}$ & 52 & 94 & 118 & 139 & 278 & 204 & 120 & 96 & 124 & 166 & 92 & 75 & 35 & 1593 \\
\hline
\end{tabular}

Fonte: os autores. 
Na Tabela 2 é mostrado o número de vezes que os termos analisados aparecem, considerando-se especificamente a categoria que se refere diretamente ao cotidiano, ou à função, do contador. É possível inferir que a contabilidade, em geral, é um assunto tratado de forma recorrente pelo jornal, pois se nota que, ao longo do período analisado, no mínimo, há a citação de dois termos, aplicados de forma direta à contabilidade.

Tabela 2 - Total de ocorrências diretas por mês - Folha de São Paulo

\begin{tabular}{llllllllllllllll}
\hline $\begin{array}{c}\text { Ocor- } \\
\text { rên- } \\
\text { cias }\end{array}$ & $\begin{array}{c}\text { Nov. } \\
\mathbf{1 3}\end{array}$ & $\begin{array}{c}\text { Dez. } \\
\mathbf{1 3}\end{array}$ & $\begin{array}{c}\text { Jan. } \\
\mathbf{1 4}\end{array}$ & $\begin{array}{c}\text { Fev. } \\
\mathbf{1 4}\end{array}$ & $\begin{array}{c}\text { Mar. } \\
\mathbf{1 4}\end{array}$ & $\begin{array}{c}\text { Abr. } \\
\mathbf{1 4}\end{array}$ & $\begin{array}{c}\text { Mai. } \\
\mathbf{1 4}\end{array}$ & $\begin{array}{c}\text { Jun. } \\
\mathbf{1 4}\end{array}$ & $\begin{array}{c}\text { Jul. } \\
\mathbf{1 4}\end{array}$ & $\begin{array}{c}\text { Ago. } \\
\mathbf{1 4}\end{array}$ & $\begin{array}{c}\text { Set. } \\
\mathbf{1 4}\end{array}$ & $\begin{array}{c}\text { Out. } \\
\mathbf{1 4}\end{array}$ & $\begin{array}{c}\text { Nov. } \\
\mathbf{1 4}\end{array}$ & Total \\
\hline $\begin{array}{c}\text { Con- } \\
\text { tador }\end{array}$ & 0 & 2 & 3 & 0 & 2 & 2 & 0 & 1 & 4 & 1 & 3 & 5 & 1 & 24 \\
$\begin{array}{c}\text { Con- } \\
\text { tábeis }\end{array}$ & 5 & 1 & 11 & 1 & 5 & 3 & 6 & 5 & 3 & 5 & 6 & 4 & 1 & 56 \\
$\begin{array}{l}\text { Con- } \\
\text { tábil }\end{array}$ & 3 & 2 & 5 & 0 & 6 & 8 & 2 & 1 & 1 & 2 & 4 & 9 & 3 & 46 \\
$\begin{array}{l}\text { Con- } \\
\text { tabili- }\end{array}$ & 9 & 16 & 13 & 1 & 13 & 11 & 9 & 3 & 8 & 16 & 7 & 7 & 4 & 117 \\
$\begin{array}{l}\text { dade } \\
\text { Total } \\
\text { por }\end{array}$ & 17 & 21 & 32 & 2 & 26 & 24 & 17 & 10 & 16 & 24 & 20 & 25 & 9 & 243 \\
mês
\end{tabular}

Fonte: os autores.

Como se percebe na Tabela 2, o termo contabilidade aparece 117 vezes dentro de um total de 243 , o que corresponde a $48 \%$ das ocorrências, isso acontece porque o Jornal utiliza essa expressão para se referir à atividade contábil de forma geral. Além disso, foi frequente a crítica ao modelo adotado pelo Governo, conhecido como "contabilidade criativa”, representando 55 eventos, ou seja, $45 \%$ de todas as ocorrências sobre a expressão contabilidade.

Ao final do levantamento, em relação ao tipo de ocorrências diretas, a pesquisa observou os seguintes resultados: relação direta com o ofício do contador, utilização de demonstrativos contábeis, possui 97 casos; notas policiais vinculadas a fraudes contábeis, 34; escândalos políticos associados à profissão do contador, 13; e IV críticas ao modelo de gestão governamental com base em demonstrativos e resultados contábeis somam 99 ocorrências.

A partir dessa classificação é possível observar que as ocorrências que apresentam uma imagem positiva do contador representam 6\% (15 casos) do número total. Entretanto, o número de representações negativas totaliza 147 ocorrências, cerca de 
60\% dos eventos, ou seja, aproximadamente 10 vezes maior que o número de positivas identificadas nesta amostra. Já em relação às ocorrências neutras, somam 34\% (81 ocorrências) do total. Esses dados comprovam que a publicidade sobre a categoria contábil é predominantemente negativa. Ainda com base nos dados levantados, é possível perceber que o Jornal Folha de São Paulo utiliza informações geradas pela Ciência Contábil para fazer críticas ao desempenho econômico do Governo, o que pode ter contribuído para associar a categoria com manobras fiscais e/ou contábeis. Dados mostram que $40 \%$ do total das notícias ligadas ao contador estão associadas a editoriais ou reportagens que destacam “manobras”, “maquiagens”, “artifícios” na contabilidade por parte do Governo Federal. Dos 99 episódios que se encaixam nesse perfil, a expressão contabilidade aparece 55,5\% das vezes, e contábeis, 28,3\%; juntas, somam 83,8\% dos casos relacionados às críticas ao Governo.

Um exemplo está no mês de maio de 2014, em uma seção denominada "Folha 10”, que destaca, segundo o periódico, o melhor da semana em 10 textos e que foi repetida durante três dias consecutivos. Entre os dias 01 e 03 do referido mês, aparece a seguinte frase: “'Troço doido’, reagiu o ministro do STF Marco Aurélio Mello, um dos poucos ao lado de Gilmar Mendes e de Joaquim Barbosa, a se pronunciar sobre a contabilidade luliana.” (FOLHA DE SÃO PAULO, 2014, grifo nosso). Nesse caso, o jornalista pretendeu criticar as demonstrações da gestão do ex-Presidente Lula, porém, é a Ciência Contábil que tem sua imagem distorcida. A forma como ele coloca "troço doido" abre a uma possível interpretação de que a contabilidade é algo desorganizado, quando se espera que reflita apenas sobre a ausência de conhecimento a respeito Ciência Contábil.

O exemplo citado não é o único; analisando-se o conjunto de reportagens que apresentam imagem negativa, pode-se perceber características associadas à categoria contábil, tais como “fraude”, “negócios suspeitos”, “corrupção”, “desvios”, “demonstrações maquiadas”, "manobras”, entre outros. Assim como a expressão "troço doido” (FOLHA DE SÃO PAULO, 2014), esses termos podem não ser aplicados na intenção de criticar a Ciência Contábil em si, porém, a forma como são colocados repetidamente pode induzir a uma compreensão de que esses episódios estão ligados à contabilidade, em vez de deixar claro que alguém, agindo de má-fé, alterou os demonstrativos.

“Com documentação falsa, um contador conseguiu abrir uma empresa há dois anos com duas sócias - uma delas estava morta desde 2005, e a outra em 2007 [...]” (ROLLI, 2013). Além desse exemplo, pode ser citado também: “Enfim, um governo responsável vai explicitar algumas dívidas e despesas hoje maquiadas pela dita ‘contabilidade criativa'[...]” (FREIRE, 2014). Outro caso que segue a mesma linha 
de redação é: “O atual governo respondeu ao dilema com uma série de artimanhas, contábeis e legais [...]” (Folha de São Paulo, 12/11/2013). Esses exemplos servem para ilustrar a forma como o Jornal se refere à contabilidade, observando-se que em nenhum momento o periódico tem a preocupação de esclarecer que a Ciência Contábil não tem responsabilidade sobre a forma como o Governo apresenta seus demonstrativos nem de informar que um contador que cometeu uma fraude é um caso isolado.

Quando o Jornal se refere diretamente ao profissional contábil, em alguns casos, ele contribui para manter uma imagem negativa sobre o contador:

Um sujeito intrépido e ambicioso se meteu a voar em um balão mesmo sem ter grande experiência em pilotagem. Para seu azar, foi logo colhido por um vendaval e levado a um local remoto e desconhecido. Não tão longe do solo, perguntou onde estava a um transeunte. "Você está a 12 metros de altura, dentro de um balão", foi a resposta. "Você, pelo jeito, é estatístico ou contador", disse, irritado, o balonista. "Sua resposta é perfeitamente precisa e absolutamente inútil.” (PATU, 2014).

No seu editorial, Patu (2014) utiliza-se de uma piada envolvendo um contador para fazer uma comparação entre uma situação negativa e o modelo de gestão econômica do Governo. O ponto que merece destaque é que aquilo que parece ser uma pequena brincadeira questiona de forma muito franca a importância da contabilidade. Além disso, conforme pesquisa de Miley e Read (2012), esse tipo de comentário é capaz de influenciar o estereótipo do profissional contábil.

Procurando entender como os estereótipos sobre a imagem do profissional contábil são construídos, foi utilizada, como base teórica, a genealogia foucaultiana, que estuda a construção dos discursos, por meio do agrupamento de sucessivos eventos aparentemente aleatórios que se unificam de tal forma que passam a compor a imagem do objeto. Dessa forma percebe-se que, do total analisado durante o período, houve 15 notícias em que o profissional contábil é apresentado como uma peça importante para o desenvolvimento da organização, enquanto em 147, a imagem do contador é associada a termos como “fraude”, “negócios suspeitos”, “corrupção”, “desvios”, “demonstrações maquiadas”, “manobras”, entre outros.

A maneira como essas expressões negativas aparecem, de forma constante e aparentemente sem uma ligação específica, contribui para que o senso comum mantenha uma imagem distorcida da categoria. Nauderer e Lima (2005) fazem uma crítica semelhante ao afirmarem que a mídia reproduz imagens tradicionais, bem como 
os estereótipos sobre as enfermeiras. Dessa forma, persiste uma discrepância entre a imagem pública das enfermeiras e a sua própria percepção como profissional, [...] “diferentemente do que acontece em outras classes, como na área do direito, na qual a imagem do profissional está ligada a ações político-associativas.” (SILVA; BORGES; BARBOSA, 2014). Isso ocorre porque as recorrências desses termos são sutilmente associadas “às categorias profissionais”, e paulatinamente o imaginário popular passa a entendê-los como características da classe.

Não foram identificadas notícias que relacionem a imagem do profissional de contabilidade a negócio formal e tradicional (FARAGALLA, 2015), nem positivamente à grande experiência inerente ao contador que exerce a função de auditor independente (KNECHEL et al., 2006) e nem a uma imagem hedonista da profissão (BALDVINSDOTTIR et al., 2009). Percebe-se que tais características não têm sido parte do noticiário do Jornal no período abordado, cabendo uma abordagem mais profunda para se identificarem os motivos da ausência dessas características nas notícias. Uma possível resposta relaciona-se à característica descritiva, e não conceitual formativa, dos fatos por parte do Jornal, o que contribui para a transmissão de uma imagem ligada às notícias veiculadas no periódico.

$\mathrm{O}$ fato de haver profissionais que promovem maquiagens e manobras e fazem mau uso da contabilidade é um dos motivos que mantêm a profissão contábil na mídia, considerando, inclusive, o impacto social associado a tais ações. Por sua vez, a propagação dessa imagem na mídia jornalística constitui um dos elementos que contribuem para a representação social do profissional de contabilidade no Brasil, conforme previsto na TRS. No entanto, o que se questiona das redações jornalísticas é o fato de seus textos não indicarem que esses maus profissionais são casos isolados que não correspondem aos princípios e valores pregados pela Ciência Contábil por meio das resoluções do Conselho Federal de Contabilidade, seu código de ética e da conduta fiscalizatória desse Órgão para todos os profissionais.

\section{CONCLUSÃO}

O objetivo neste trabalho foi verificar como a imagem do profissional de contabilidade vem sendo veiculada nas notícias evidenciadas em um jornal de grande circulação no Brasil. A partir da análise dos dados pôde-se constatar que, ao longo do ano, o periódico Folha de São Paulo tem associado as expressões contador, contabilidade, contábil e contábeis, principalmente, a notícias com um contexto negativo, especialmente quando associa a contabilidade a escândalos políticos, com fraudes 
investigadas pela polícia, e também quando questiona a gestão econômica do Governo, o qual lançou mão da chamada “contabilidade criativa” para manter superávit em suas demonstrações.

Como resultado do objetivo específico 1 e considerando-se que é um jornal de grande circulação e influência no País, pode-se perceber que a recorrência de notícias com imagem negativa, que somam um total de 147, é aproximadamente dez vezes maior que as reportagens que apresentam imagem positiva (15 notícias) associada à figura do contador. Esse quadro pode contribuir para a manutenção de uma representação social do profissional contábil limitado aos relatórios e demonstrações que nem sempre se aplicam à realidade, sendo estes vistos como um "troço doido" (FOLHA DE SÃO PAULO, 2014b, p. 17).

Nesse sentido, a genealogia foucaultiana mostra sua aplicabilidade, uma vez que se percebe a ocorrência constante de símbolos e imagens negativas sendo associados à representação do contador. Como resultado do objetivo específico 2, foi identificado que os termos fraude, negócios suspeitos, corrupção, desvios, demonstrações maquiadas, manobras, entre outros, estão comumente associados à contabilidade e ao contador.

Essas recorrências atingem o imaginário popular, em razão do poder de discurso que a mídia possui e passam a agregar paulatinamente a forma de apreensão do objeto (MOSCOVICI, 2003). Assim, por meio desses eventos, aparentemente aleatórios, é construída e reconstruída a forma de entender a contabilidade e, dessa mesma, forma o senso comum percebe o profissional contábil de forma caricata.

Uma das limitações desta pesquisa é que não foi possível proceder uma análise mais profunda sobre o Jornal, e seus discursos, utilizado como fonte. Para tanto, faz-se necessário responder a um conjunto de perguntas, como: qual o objetivo em noticiar determinada reportagem? Qual o espaço utilizado na matéria? Qual a relação do Jornal com o mercado? Qual a publicidade sobre o tema? Como ocorreu a recepção do público? Esses questionamentos ficam como sugestão para futuras pesquisas, as quais podem ajudar a categoria contábil a melhorar a veiculação de sua imagem por meio dos periódicos.

\section{REFERÊNCIAS}

ANDRADE, M. M. Como preparar trabalhos para cursos de pós-graduação: noções práticas. 5. ed. São Paulo: Atlas, 2002. 
BALDVINSDOTTIR, G. et al. The image of accountants: from bean counters to extreme accountants. Accounting, Auditing \& Accountability Journal, v. 22, i. 6, p. 858-882, 2009.

BARDIN, L. Análise de conteúdo. Lisboa: Edições 70, 1979.

BOMFIM, M. Uso de padrão mundial em relatórios favorece contadores. Folha de São Paulo, 25 set. 2014. Disponível em: <http://www1.folha.uol.com.br/educacao/2014/09/1521907-uso-de-padrao-mundial-favorece-contadores.shtml>. Acesso em: 02 dez. 2014.

CARVALHO, F. A. L. de. O conceito de representações coletivas segundo Roger Chartier. Diálogos, Maringá: UEM, v. 9, n. 1, p. 143-165, 2005.

CHARTIER, R. A história cultural: entre práticas e representações. Rio de Janeiro: Bertrand Brasil, 1990.

\section{CONSELHO REGIONAL DE CONTABILIDADE DA BAHIA. Relatórios e}

Dados Estatísticos. Disponível em: <www.crcba.org.br/new/institucional-2/fiscalizacao/atividades-desenvolvidas-20132014>. Acesso em: 02 dez. 2014.

CRUZ, F. S. da. “Os movimentos sociais e a mídia em tempos de globalização: um estudo das abordagens de jornais Brasileiros e Espanhóis sobre o MST e os direitos humanos.” Revista Famecos - Mídia, Cultura e Tecnologia, v. 19, n. 3, 2012. ECHENOZ, J. Coisa de quinze dias, no máximo. Folha de São Paulo, 12 out. 2014. Disponível em: <http://www1.folha.uol.com.br/paywall/signup-colunista. shtml?http://www1.folha.uol.com.br/fsp/ilustrissima/190216-coisa-de-quinze-dias-no-maximo.shtml>. Acesso em: 02 dez. 2014.

EVANS, L.; FRASER, I. The accountant's social background and stereotype in popular culture; The novels of Alexander Clark Smith. Accounting, Auditing \& Accountability Journal, v. 25, i. 6, p. 964-1000, 2012.

FAÉ, R. A Genealogia Em Foucault. Psicologia em Estudo, Maringá, v. 9, n. 3, p. 409-416, set./dez. 2004.

FARAGALLA, W. A. Stereotypes Regarding Accounting Profession: An Empirical Study. Management Intercultural, v. 17, i. 33, p. 151-155, Apr. 2015. 
FERREIRA, K Z. Quando o professor é notícia? Imagens de professor e imagens do jornalismo. 2012. 190 p. Tese (Doutorado em Educação)-Universidade de São Paulo, São Paulo, 2012.

FISCHBERG, J. Jornais E Sites De Notícia: O Que Leem (Ou Não Leem) Futuros Professores. 2011. 193 p. Tese (Doutorado em Educação)-Pontifícia Universidade Católica do Rio de janeiro, Rio de Janeiro, 2011.

FOLHA DE SÃO PAULO. Classificados. 09 mar. 2014a.

FOLHA DE SÃO PAULO. Editorial 100\% público. 24 abr. 2014b. Disponível em: $<$ http://acervo.folha.uol.com.br/fsp/2014/05/01/661>, pág. 17. Acesso em: 02 dez. 2014.

FOUCAULT, M. Microfisica do poder. Rio de Janeiro: GRAAL, 1979.

FOUCAULT, M. Vigiar e punir: nascimento da prisão. 34. ed. Petrópolis: Vozes, 2007.

FREIRE, V. T. Aumento de imposto em 2015. Folha de São Paulo, 01 out. 2014. Disponível em: <http://www1.folha.uol.com.br/colunas/viniciustorres/2014/10/1525215-aumento-de-imposto-em-2015.shtml>. Acesso em: 02 dez. 2014.

FRUTOS, F. P. P.; CRUCIOL, C. V. Administração e Psicologia: Dialogando por meio das representações sociais. In: ENCONTRO DE ESTUDOS ORGANIZACIONAIS DA ANPAD, 5., 2008, Belo Horizonte. Anais... Belo Horizonte: ANPAD, 2008. GIL, A. C. Métodos e Técnicas da Pesquisa Social. 6. ed. São Paulo: Atlas, 2008.

GRILO, G. B. A efetiva observância de aspectos éticos na prestação de serviços pelo profissional contábil feirense face à concorrência na cidade. 2011. 86 p. Trabalho de Conclusão de Curso (Graduação em Ciências Contábeis)-Universidade Estadual de Feira de Santana, Feira de Santana, 2011.

GUERRA, G. C. M. et al. A Representação Social da Profissão de Contador na Perspectiva dos Profissionais da Contabilidade. Revista de Contabilidade e Organizações, USP, v. 5, n. 12, p. 157-171, 2011.

HOBSBAWM, E. J. A era das revoluções: Europa 1789-1848. 3. ed. Rio de Janeiro: Paz e Terra, 1981. 
KNECHEL, W. et al. The Demand Attributes of Assurance Services Providers and the Role of Independent Accountants. International Journal of Auditing, v. 10, i. 2, p. 143-162, 2006.

LIMA, M. M. S. de. O uso da informação contábil no setor sucroalcooleiro: um estudo nas indústrias de Alagoas. 2006. 107 p. Dissertação (Mestrado em Ciências Contábeis)-Programa Multiinstitucional e Inter-Regional de Pós-Graduação em Ciências Contábeis, UnB/UFPB/UFPE/UFRN, Natal, 2006.

LUCA, T. R. de. História dos, nos e por meio dos periódicos. In: PINSKY, C. B. (Org.). Fontes históricas. São Paulo: Contexto, 2005.

MACÊDO, A. F. P. de et al. Diálogos entre a Administração e Contabilidade: Reflexão sobre as Representações dos Professores. Sociedade, Contabilidade e Gestão, v. 3, n. 2, 2010.

MILEY, F.; READ, A. Jokes in popular culture: the characterization of the accountant. Accounting, Auditing \& Accountability Journal, v. 25, i. 4, p. 703-718, 2012.

MOLINARI, S. K. R.; RICCIO, E. L. O perfil psicológico do estudante de contabilidade da FEA/USP. In: CONGRESSO DE CONTROLADORIA E CONTABILIDADE DA USP, 4., 2004, São Paulo. Anais... São Paulo, out. 2004.

MORAIS, J. J. da S. A representação social do contador e a imagem dele perante a sociedade. Revista Studia Diversa, CCAE-UFPB, v. 1, n. 1, out. 2007.

MOSCOVICI, S. A representação social da psicanálise. Rio de Janeiro: Zahar, 1978.

MOSCOVICI, S. Representações Sociais: investigação em psicologia social. Petrópolis: Vozes, 2003.

MURCIA, F. D.; BORBA, J. A. Um estudo das fraudes contábeis sob duas óticas: Jornais econômicos versus periódicos acadêmicos no período de 2001-2004. Revista de Contabilidade do Mestrado em Ciências Contábeis da UERJ, v. 10, n. 2, p. 99-114, 2005.

NAUDERER, M. T.; LIMA, M. A. D. da S. Imagem da enfermeira: revisão da literatura. Revista Brasileira de Enfermagem, v. 58, n. 1, p. 74-77, jan./fev. 2005. 
NEVES, A. 'Tancredo contava contos de assombração'. Folha de São Paulo, 04 out. 2014. Disponível em: <http://www1.folha.uol.com.br/folhinha/2014/10/1526701-aecio-neves-tancredo-contava-contos-de-assombracao.shtml>. Acesso em: $02 \mathrm{dez}$. 2014.

NEVES, J. L. Pesquisa Qualitativa: Usos e Possibilidades. Caderno de Pesquisa em Administração, São Paulo, v. 1, n. 3, jul./dez. 1996.

NORONHA, P. L. R. de; SANTANA, C. M.; NUNES, D. M. S. Percepção de classe: estudo com profissionais contadores no distrito federal. Universidade de São Paulo. Disponível em: <www.congressousp.fipecafi.org/artigos92009/445. pdf>. Acesso em: 12 jun. 2013.

OLIVEIRA, S. R. de; SILVEIRA, C. da S. O trabalho como representação: a visão dos jovens universitários. In: ENCONTRO DE GESTÃO DE PESSOAS E RELAÇÕES DE TRABALHO, 1., 1998, Rio de Janeiro. Anais... Rio de Janeiro: ANPAD, 1998.

PATU, G. A piada do balonista. Folha de São Paulo, São Paulo, p. A4, 13 jan. 2014.

PINSKY, C. B. Fontes históricas. São Paulo: Contexto, 2005.

ROLLI, C. Receita desmonta fraude em venda de papel sem tributos. Folha de São Paulo, 13 dez. 2013. Disponível em: <http://www1.folha.uol.com.br/paywall/signup-colunista.shtml?http://www1.folha.uol.com.br/fsp/mercado/143446-receita-desmonta-fraude-em-venda-de-papel-sem-tributos.shtml>. Acesso em: 12 jan. 2013. SANTANA, A. R.; FARIA, J. A. O perfil dos estudantes recém-ingressos no curso de Ciências Contábeis: uma análise à luz da teoria das representações sociais. In: ENCONTRO NORDESTINO DE CONTABILISTAS, 11., 2013, Aracaju. Anais... Aracaju, 2013.

SILVA, C. A. T.; FLOR, C. V. A. A Imagem do contador na imprensa jornalística brasileira. Revista Brasileira de Contabilidade, Brasília, DF, p. 61-72, 2013.

SILVA, S. S. da; BORGES, L. de O.; BARBOSA, S. da C. A profissão de advogado conforme apresentada em jornais paraibanos. Psicologia \& Sociedade, v. 26, n. 3, p. 652-663, 2014.

STARK, J. A. Contabilidade de Custos. São Paulo: Pearson Education do Brasil, 2007. 
WARREN, S.; PARKER, L. Bean counters or bright young things? Towards the visual study of identity construction among professional accountants. Qualitative Research in Accounting \& Management, v. 6, n. 4, p. 205-223, 2009.

WILLIAMS, J. Pós-estruturalismo. Tradução Caio Liuduig. Petrópolis: Vozes, 2012.

YARED, M. L. de M. A Representação da corrupção pela imprensa escrita - uma perspectiva pela análise de discurso crítica. 2011. 134 p. Dissertação (Mestrado em Linguística)-Universidade de Brasília, Brasília, DF, 2011.

Como citar este artigo:

\section{ABNT}

FARIA, Juliano Almeida; MIRANDA, Vinícius de Lacerda. Caricaturas e estereótipos do contador: como a imagem do profissional de contabilidade vem sendo veiculada em um jornal de grande circulação no Brasil? RACE, Revista de Administração, Contabilidade e Economia, Joaçaba: Ed. Unoesc, v. 15, n. 3, p. 1087-1116, set./dez. 2016. Disponível em: <http://editora.unoesc.edu.br/index.php/race>. Acesso em: dia/mês/ano.

\section{APA}

Faria, J. A., \& Miranda, V. de L. (2016). Caricaturas e estereótipos do contador: como a imagem do profissional de contabilidade vem sendo veiculada em um jornal de grande circulação no Brasil? RACE, Revista de Administração, Contabilidade e Economia, 15(3), 1087-1116. Recuperado em dia/mês/ano, de http://editora.unoesc. edu.br/index.php/race 
